\title{
PODER JUDICIAL Y PODERES IRRESTRICTOS: CONTRA EL IMPERIO DE LA ARBITRARIEDAD
}

\author{
Ricardo Cueva Fernández \\ Universidad Autónoma de Madrid
}

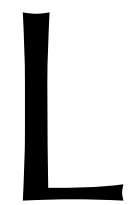

os trabajos de Liborio HIERRO y Francisco Javier LAPORTA han formado parte habitualmente de la teoría y de la filosofía del Derecho. En este sentido, es claro que sus incursiones en la pura filosofía política han sido menos amplias, y su preocupación por mecanismos institucionales se ha centrado en la indagación sobre el papel de jueces y tribunales en la aplicación del Derecho. De otra parte, su noción acerca de la democracia, a pesar de ser muy robusta, sin embargo tampoco ha implicado estudios empíricos o sociológicos sobre su alcance: para ser exactos, digamos que sus aproximaciones a la teoría democrática han sido más que suficientes para formular sus ideas sobre el Derecho. Y por todo ello entiendo que ambos profesores han logrado mantener una grandísima coherencia en todos sus planteamientos sin tener que sumergirse en tediosos ejercicios de detalle. Estas líneas, sin embargo, tratan de recuperar cierto problema en la teoría política pero también en la filosofía del Derecho contemporáneas que no deberíamos obviar si queremos extraer lecciones adecuadas de sus escritos.

Quizás la mejor manera de exponer el asunto sea el artículo de Liborio HIERRO, más tarde publicado en Estado de Derecho: Problemas actuales, y titulado «Democracia y poder judicial». En este texto su autor venía a recuperar el concepto de democracia de la mano de BOBBIO y se centraba en la de tipo político, omitiendo la actitud humana y la dimensión económica que pudiera tener el término, con el fin de aposentar su tema de estudio en aquellas líneas (47). Recordemos a tales efectos que BOBBIO citaba como las seis reglas características de la democracia: a) la igualdad, en el sentido de que todos los mayores de edad gozan de los derechos políticos, como el de expresar con el voto la opinión propia y/o designar a quien la exprese por ellos; $b$ ) la regla del voto según el mismo peso; c) la de la libertad en sentido de ser libres para votar según su propia opinión, conformada en el mayor grado posible de manera libre; $d$ ) pluralidad (deben existir alternativas reales para elegir); e) regla de la mayoría numérica para tomar las decisiones, y f) la de protección de minorías (ninguna resolución de la mayoría puede limitar los derechos de la minoría y de modo particular el de convertirse en mayoría).

También ahí mismo el profesor HIERRO se hacía eco de Alf Ross, cuando el autor danés afirmaba en uno de sus trabajos de 1958 que «el poder político pertenece en derecho a la población toda y no meramente a una persona singular o grupo específico y limitado de gentes» (cit. por HIERRO, 47). Esto a su vez supondría que el poder de hacer leyes provendría de un órgano supremo, a saber, de una asamblea representativa. 
A continuación el académico español afirma que el sistema judicial es «un subsistema dentro del propio sistema normativo» (49, las cursivas de aquí en adelante son propias, excepto indicación contraria), poseyendo las siguientes características: a) carácter regulador, es decir, los conflictos sociales se resuelven de acuerdo a normas previamente reconocida; $b$ ) carácter institucional, porque la adjudicación de esas normas corresponde a un individuo (juzgador) o grupo de individuos (tribunal) que están institucionalmente preestablecidos y resultan ser independientes de las partes en conflicto; c) carácter contencioso, en tanto en cuanto las partes en conflicto tiene la posibilidad de manifestar su posición sobre hechos y normas aplicables; $d$ ) carácter rogado, porque el juez debe decidir solo sobre lo alegado al respecto y, por último, y e) carácter motivado, porque el órgano judicial debe fundamentar su decisión (50).

A su vez, el profesor HIERRO explica que estos rasgos implicarían referirse también a un rol que podría denominarse «judicial». «Esa exclusiva vinculación a la Ley es, al mismo tiempo, descriptiva y normativa: define el rol judicial y justifica su poder» (50). En consecuencia, el poder judicial no sería tal «poder», no estaría atribuido a un presunto colectivo de jueces y magistrados, sino a sus órganos individualizados y en tercer y último lugar, la independencia judicial sería la condición necesaria para garantizar el sometimiento de los Juzgados y Tribunales a la Ley, de modo que no tendría una legitimación política distinta a los otros «poderes» ni configuraría una exigencia para una compensación o equilibrio entre poderes políticos de distinto origen o composición (como puede serlo el reparto de competencias (51) en un estado federal o autonómico, o como lo es hoy el poder de control del Parlamento sobre el ejecutivo (52). La actividad judicial no es independencia de la actividad normativa del Gobierno y tampoco es exclusivamente independencia frente al Gobierno. El poder judicial independiente no es teóricamente incompatible con un sistema no democrático, y garantizaría la seguridad jurídica. «La independencia judicial no es en definitiva la garantía de la Democracia, sino una consecuencia necesaria de ella», aunque no sea concebible una democracia sin poder judicial independiente (53) y la democracia legitime al poder judicial (54). El poder judicial no aporta legitimación específica alguna, pero «se contagia de la legitimidad democrática de la ley» (54), y «un poder judicial independiente es $e l$ instrumento adecuado para combatir el abuso, la desviación o la corrupción de cualquier detentador del poder» (56).

Por su parte, el profesor LAPORTA apunta a conclusiones parecidas en el libro El imperio de la ley. En el volumen, concretamente en su capítulo X, y tras varias páginas en las que se refiere a las objeciones democráticas a la Constitución, parece mostrarse favorable al atrincheramiento de ciertas cláusulas sobre derechos. Para ello procede a «establecer una distinción clara entre lo que pueden llamarse principios o exigencias ético-políticas y lo que llamaré mecanismos institucionales». De esta forma, y de seguido, el profesor LAPORTA señala que aunque se hable con frecuencia del principio de separación de poderes o del federal «como si se tratara de exigencias éticas o políticas», en realidad «estamos simplemente ante dos construcciones institucionales, ante dos mecanismos». Su incorporación constitucional obedece a que «son articulaciones normativas que desarrollan o sirven de vehículo a la realización de principios». Así que «las razones para el precompromiso constitucional justificarían los mecanismos de precompromiso, de forma tal que las construcciones institucionales y su protección 
constitucional tuvieran que exhibir las razones que los apoyan» (233, las cursivas son aquí del autor).

Así, continúa LAPORTA, «si nos preguntáramos, por ejemplo, por la justificación del mecanismo normativo de las separación de poderes podríamos aducir con cierta plausibilidad la exigencia de independencia judicial para la protección de los derechos individuales frente al poder ejecutivo, pero ni nos interrogásemos sobre la conveniencia de constitucionalizar, por ejemplo, el déficit cero o al independencia del banco emisor, seguramente no nos sentiríamos satisfechos porque algunos economistas nos dijeran que las mayoría toman sus decisiones con tendenciosidad o con miopía de futuro» (233 y 234). En consecuencia, la conclusión del profesor es clara: «solo los principios o razones que recogen derechos individuales básicos o descansan en ellos son lo suficientemente poderosos como para medirse con la objeción contramayoritaria» (234).

Por otra parte, el modelo de juez que el autor de El imperio de la ley defiende, a su vez, es muy similar al sostenido por Liborio HIERRO. Así, tiene el deber de «aplicar el Derecho», de resolver los conflictos; pero además ha de hacerlo recurriendo a los «ingredientes del ordenamiento jurídico», ateniéndose a su sistema de fuentes establecido por los criterios de identificación de las normas jurídicas y motivar las sentencias, justificándolas con razones (de nuevo, 194, también en 212). En esta dimensión el Derecho no sería algo radicalmente indeterminado, al contrario de lo que aseveran los seguidores de los Critical Legal Studies y otros (196 y 197). El razonamiento moral, sin embargo, no es arbitrario ni particularista, sino que quedaría circunscrito mediante controles de racionalidad y sustentado en enunciados generales (199), lo cual no le impediría al juez emprender cierta discreción (debido a lagunas y antinomias principalmente) e incluso la creación de normas (207-214), siempre merced a cierta coherencia con el ordenamiento (214-218).

Las diferencias y similitudes entre ambos profesores aquí son evidentes, aunque yo diría que el balance señala cierta complementariedad. Mientras que los uno y otro abogan por un juez que no se despegue de la ley (en el caso de LAPORTA, particularmente de la coherencia del ordenamiento como un todo), HIERRO hace hincapié en la legitimidad democrática de las normas y desmenuza los presupuestos habituales de la separación de poderes en torno a jueces y tribunales, pero se puede afirmar sin lugar a dudas que ninguno de ellos concede papel preeminente al poder judicial y que por tanto no siguen la lectura clásica de la división de poder ejecutivo, legislativo y judicial, que durante tantos años se ha enseñado en las asignaturas de Derecho político o Constitucional de las Universidades españolas.

Ahora bien, cabe destacar en primer término, el gran equívoco de la exposición tradicional. En primer lugar, porque la famosa exposición de MONTESQUIEU pertenece a una sociedad de carácter estamental, en la cual el poder judicial correspondía a la denominada «nobleza de toga». Es más, su pensamiento contemplaba diversos regímenes de gobierno (democracia, aristocracia y monarquía) a la manera clásica de ARISTÓTELES y en medio de ordenamientos que todavía se estaban abriendo a la Ilustración. Por no hablar de su versión de la «constitución inglesa», que venía a acoger precisamente un artefacto jurídico-político no adoptado en general luego por ninguna de las naciones europeas ni del mundo en general, por mucho que todas hayan sido o sean «democracias constitucionales». 
El equívoco prosigue bastante después de MONTESQUiEU, incluso, y fue alimentado por KANT (cit. en la p. 48 de la obra de HIERRO). Concretamente merced al ejemplo de la revolución norteamericana y las sucesivas constituciones con las que se dotaron los trece estados dimanados de las trece colonias de la antigua metrópolis británica. En realidad, y si nos fijamos en ellas observaremos que tan solo en algunas se erigió un bicameralismo que por los demás no tenía las connotaciones nobiliarias de Europa. Es más, el poder judicial no asoma en casi ninguna de ellas como independiente propiamente dicho y el jurado en cambio está presente en todas partes (CUEVA, 2011: 321 y $322,331)$.

El gran giro se produce en realidad con la Constitución federal de 1787, cuando en su art. VI afirma que «esta Constitución, y las leyes de los Estados Unidos que se expidan con arreglo a ella, y todos los tratados celebrados o que se celebren bajo la autoridad de los Estados Unidos, serán la suprema ley del país y los jueces de cada Estado estarán obligados a observarlos, aun cuando se encuentre en la Constitución o en las leyes de cualquier Estado alguna disposición que lo contradiga». Tal precepto, en combinación con la identificación del «poder judicial» con el Tribunal Supremo del país (sec. 1 del art. III), pretendía otorgar seguridad jurídica a propietarios, acreedores y el general a comerciantes extranjeros frente a las decisiones que a veces tomaban individualmente los Estados para ignorar contratos, testamentos o inmuebles que habían pertenecido, por ejemplo, a lealistas durante la guerra con la metrópoli británica (CUEVA, 2011: 338 y 339, y 2015: 291). Aprovechando esa urgencia, al tiempo, se intenta erigir un árbitro que permita conservar la Unión sin riesgos secesionistas. El Federalista fue claro al respecto: «el departamento judicial es, sin comparación, el más débil de los tres departamentos del poder», de modo que «nunca podrá atacar con éxito a ninguno de los otros dos», y «son precisas toda suerte de precauciones para capacitarlo a fin de que pueda defenderse de los ataques de aquellos». Y «la independencia completa de los tribunales de justicia es particularmente esencial en una Constitución limitada», siendo su deber el de «declarar nulos todos los actos contrarios al sentido evidente de la Constitución» (El Federalista, núm. 78: 331 y 332 ).

Lo que permaneció erigido, pues, y eso lo detectan muy bien los profesores HiERRO y LAPORTA, como vemos fue la idea de un «poder moderador» (HIERRO, op. cit., 49) que evitara colisiones, por ejemplo, entre los distintos Estados, pero también entre ciudadanos o corporaciones y gobierno, tal y como demuestran los primeros casos que se plantearon ante aquel. Ambos autores observan así que el poder judicial se debe al «imperio del derecho» (en palabras de LAPORTA, op. cit., 218), o a su «función pública» de administrar justicia (en términos de HIERRO, op. cit., 51) o «exclusiva dependencia de la ley» (ibid., 52), que permite la seguridad jurídica merced a la imparcialidad desplegada. Este discurso es posible verterlo, sin mayores problemas, en el ámbito de la aplicación del Derecho si entendemos que este resulta legítimo. Ahora bien, ¿cuándo lo es realmente? HIERRO afronta esta pregunta con rotundidad al señalar que los jueces añaden legitimidad pero que no la suministran propiamente (53), o cuando (y en esto, al contrario que LAPORTA) se refiere al reparto competencial entre territorios. Y otra más robusta cuando nos referimos al requisito de la pluralidad mencionado por BoBBIO en su teoría de la democracia. 
En efecto, recordemos que uno de los rasgos que el pensador italiano atribuía a la democracia era la posibilidad de que existieran realmente alternativas, una pluralidad de opciones, así como que los ciudadanos pudieran conformar sus opiniones con la mayor libertad posible. Lo cual nos conduce a considerar cuál es esa garantía. Quizás no se trate más que de una cuestión baladí, pero no acabo de verlo de este modo. A los profesores LAPORTA y HIERRO les preocupa mucho, y dígase tal cosa como elogio a su favor, el respeto a la ley de jueces y tribunales, así como la legitimación democrática de aquella (en el supuesto del segundo, extendida a la esfera local o territorial con mayor querencia). Pero lo que aquí mantengo es que tales premisas no serán nunca respetadas si no existe una división del poder que lo permita. Una condición necesaria, aunque no suficiente (quizás ningún lote de instituciones resulte satisfactorio del todo, en este sentido) para apuntalar el autogobierno democrático, pero en cualquier caso, constitutiva. Un requisito indispensable con el fin de alimentar los variados canales de la opinión pública y la vigilancia mutua entre detentadores del poder en distintas residencias. El carácter sólido del republicanismo proviene de este entendimiento. Los jueces y tribunales pensarán que aplican la ley de manera estricta y sin extralimitarse (¿quién vigilará que cumplan su «rol»?), el gobierno podrá quedar muy satisfecho con hacer cumplir sus mandatos (¿qué asamblea a salvo de la corrupción lo controlará?) y la paz social parecerá algo similar a la seguridad jurídica aunque una minoría atrinchere prebendas y fugue capitales. Y es que aunque esta seguridad pueda fundamentar unos supuestos «planes de vida» individuales, ninguno de ellos podrá afianzarse sin una garantía colectiva. Si tal aseguramiento no se produce el ciudadano estará sometido a la más siniestra arbitrariedad, desprovisto de la defensa necesaria para comprenderse socialmente. Lo que preocupaba la fórmula republicana política cuyo sendero durante mucho tiempo fue paralelo al de la democracia es este principio (que no mecanismo).

Otra cosa es que la separación de poderes habitual en la teoría política y jurídica de cierto cuño resulte insuficiente hoy en día. El poder judicial es un instrumento adecuado para combatir la corrupción, pero no (y quizás nunca lo haya sido antes) $e l$ instrumento por excelencia. La independencia judicial no resulta ser la garantía de la democracia, ciertamente, pero todo sistema democrático exige división del poder (territorial o de otros tipos, lo cual requiere preguntarse sobre la naturaleza y el despliegue de los poderes que realmente actúan hoy en la sociedad de manera intensa). Y tal descubrimiento no debería conducirnos a abandonar esa dispersión saludable, sino a reforzar antiguas instituciones y recrear otras nuevas que impidan la arbitrariedad, es decir, que eviten el gobierno de la facción, de un grupo hegemónico de intereses que socave el bien común.

En este sentido, de todas formas, la cura escéptica que ofrece HIERRO y la desconfianza frente a la discrecionalidad judicial de LAPORTA son poderosas herramientas para emprender ese diseño institucional necesario para la democracia. La división de poderes contribuye a la legitimidad del sistema, a impedir su corrupción por el domino de una facción determinada que impida la pluralidad y la posibilidad de elegir alternativas reales. 


\section{BIBLIOGRAFÍA CITADA}

BobBio, N., 1977: «Democracia representativa y teoría marxista del Estado», Sistema, núm. 16: $3-30$.

Cueva Fernández, R., 2011: De los niveladores a Marbury vs. Madison: los orígenes de la democracia constitucional, Madrid: Centro de Estudios Políticos y Constitucionales.

- 2015: «¿Qué federalismo? La república estadounidense originaria y las tribulaciones de Publius», Anales de la Cátedra Francisco Suárez, 49: 281-309.

Hamilton, A.; Jay, J., y Madison, J., 2011: The Federalist Papers (1787-1788); trad. cast. de Gustavo R. Velasco, por donde se cita, El Federalista, 2. ${ }^{a}$ ed. (1. a ed. de 1943), México: Fondo de Cultura Económica, 2001.

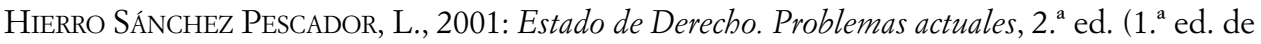
1998), México D.F.: Fontamara.

LAPORTA SAn Miguel, F. J., 2007: El imperio de la ley. Una visión actual, Madrid: Trotta.

Ross, A., 1958: On Law and Justice, London: Steven \& Sons. 